\title{
SCALE EFFECT IN DIRECT SHEAR TESTS ON RECYCLED CONCRETE AGGREGATE
}

\author{
EMIL SOBÓL, WOJCIECH SAS, ALOJZY SZYMAŃSKI \\ Warsaw University of Life Sciences - SGGW, Faculty of Civil and Environmental Engineering, \\ ul. Nowoursynowska 159, 02-776 Warsaw, Poland, \\ e-mail: emil_sobol@sggw.pl, alojzy_szymanski@sggw.pl,wojciech_sas@sggw.pl
}

\begin{abstract}
The depletion of natural resources is forcing researchers to explore the possibilities of new aggregates, such as recycled concrete aggregate (RCA). In this article, the mechanical properties and the influence of the size of the direct shear box on the obtained parameters were examined. The study was conducted in two apparatus: medium $(120 \times 120 \mathrm{~mm})$ and large $(250 \times 250 \mathrm{~mm})$. In each of these devices, a total of 6 tests were performed: 3 for dry sample and 3 at optimum moisture content. From the results, the conclusions described below have been drawn.
\end{abstract}

Key words: direct shear test, recycled concrete aggregate, scale effect, box size

\section{INTRODUCTION}

The problem of the increasing amount of construction waste, such as concrete or bricks, in addition to the simultaneous depletion of natural resources, leads engineers and scientists to seek new alternative aggregates [16]. The obvious and natural step is to reuse the construction waste as a recycled concrete aggregate (RCA). Global trend in this direction has led to the creation of a vast body of work and many research projects. In 2004, Norwegian scientists created a 4-year test program designed to prove the suitability of RCA as a substructure for E6 highway [1], [2]. Meanhwile in China, the dynamic expansion of the country has led to a significant increase in the amount of construction waste. Thus research began on the use of RCA as a standard road sub-base [13]. Intensive studies led to the publication of the first RCA reuse standard in 2007 [4].

Increase in the use of recycled materials is accompanied by the extension of the research conducted on it. Research was performed on high-strength concrete with addition of recycled aggregates [9]. The subject of this test has been the effect of different classes of RCA on concrete strength [11]. Typical tests for road substructures suitability have also been carried out: CBR [14], permeability tests [15], compatibility, susceptibility to crushing, frost resistance and triaxial compression test [1], [2].

\section{LITERATURE REVIEW}

Conducting the test in a direct shear apparatus is a simple and fast method to find the angle of friction and cohesion in soils. However, during this test there arose a problem regarding the size of the box and its effect on the results achieved. In 1938, Taylor and Leps started working on this issue. They studied the dried Ottawa sand in both small $(76 \mathrm{~mm})$ and large (305 mm) square box. They found that the friction angle $\varphi^{\prime}$ obtained from the test in large apparatus is less than about $0.5^{\circ}$ smaller than the result obtained with a small box [17].

Bishop dealt with the same problem. He used two square boxes, whose dimensions were $60 \mathrm{~mm}$ and $305 \mathrm{~mm}$. The research material was dry sand with its porosity being between 0.36 and 0.46 . The angle that he obtained from the test in a small box was about $2^{\circ}$ higher than the values obtained with the use of a large apparatus. Bishop also examined the effect of particle size of gravel grains with a maximum size of $32 \mathrm{~mm}$ on the behaviour of the shear. He said that the large grains have no significant impact on the process [4].

Palmeria and Milligan also studied the problem of scale effect. In their own research, they used three sizes of boxes: $1 \mathrm{~m}$ cubic, rectangular $252 \times 152 \times 152 \mathrm{~mm}$ box and square $60 \times 60 \times 32 \mathrm{~mm}$ box. The research material was dry Leighton Buzzard silica sand, whose 
$\mathrm{D}_{50}$ was $0.65 \mathrm{~mm}$. The results for all three boxes were in the range between $49^{\circ}$ and $50^{\circ}$ [12].

In 2008, Bareither, Benson and Edil published extensive research concerning the scale effect in relation to sand with various gravel content. They performed tests on 30 samples in small $(64 \times 64 \mathrm{~mm})$ and large $(305 \times 305 \mathrm{~mm})$ direct shear apparatus. In their research, the $\mathrm{L} / \mathrm{D}_{50}(\mathrm{~L}-$ length of the shear box) ratio was equal from 93 to 2033. They found that in the case of the sand with less than $30 \%$ gravel content, the results obtained with the use of the small and large direct shear apparatus are so similar, that in both cases the research gave reliable values. However, in the case of sand with a different gravel content, the size of the box should be taken into consideration [3].

Research on the scale effect have been carried by Cerato and Lutenegger. They examined four types of sands and one type of gravel. The analysis was conducted on three direct shear apparatus with boxes whose dimensions were as follows: $60 \times 60 \times 26.4 \mathrm{~mm}$, $102 \times 102 \times 40.6 \mathrm{~mm}$ and $305 \times 305 \times 177,8 \mathrm{~mm}$. All samples were tested at three different densities. It was found that with the increase in density, differences in the results between a small and large apparatus decrease. The only exception was the Ottawa sand. The results obtained for this material were the same for all three apparatus at different densities. The authors explained that this was due to the Ottawa sand having the biggest $L / D_{50}$ ratio [5]. Jewell and Worth studied the effect of $L / D_{50}$ ratio. They proved that for $L / D_{50} \geq 50$, the grain size does not cause the scale effect [7].

Moayed and Alizadeli examined impact of silt content of scale effect. They performed studies on two devices, a small $(60 \times 60 \mathrm{~mm})$ one and a medium $(100 \times 100 \mathrm{~mm})$ one. The tests included a study on Firuzkuh sand, both pure and with the addition of
10,20 and $30 \%$ of silt. Test was conducted on compacted sand, adjusted to optimum moisture content. On the basis of the results it was concluded that the peak shear force decreases with the increase in box size and silt content [10].

In 2010, the problem of scale effect in clayey sands was investigated. A total of 45 direct shear tests of this soil, whose density ranged from 1.67 to $1.82 \mathrm{~g} / \mathrm{cm}^{3}$, were conducted. Shearing was carried out in three square boxes with dimensions 60 , 100 and $300 \mathrm{~mm}$. The study clearly showed that the increase of the box size is followed by the increase in cohesion, and the decrease of the friction angle [6].

The next step in the study of scale effect was made by Zhou. He believed that the scale effect does not depend only on the grain size of the test material. Examining variability, shape, rotation, slip grains, the average volume of the sample, the distribution of shear stress and development of shear zones, the author showed that the largest factor influencing the bulk friction is the rotation of grains during the test [18].

The complexity of the problem of scale effect inspired the authors of this article to test strength properties of the recycled concrete aggregate (RCA). Taking into account previous discoveries and innovations will allow us to take a reliable view at the resulting parameters and seriously consider the use of RCA as a material for construction land.

\section{MATERIALS AND METHOD}

The test material is crushed concrete, class C16/20 to $\mathrm{C} 30 / 35$, coming from demolished buildings. Sieve analysis showed that it should be classi-

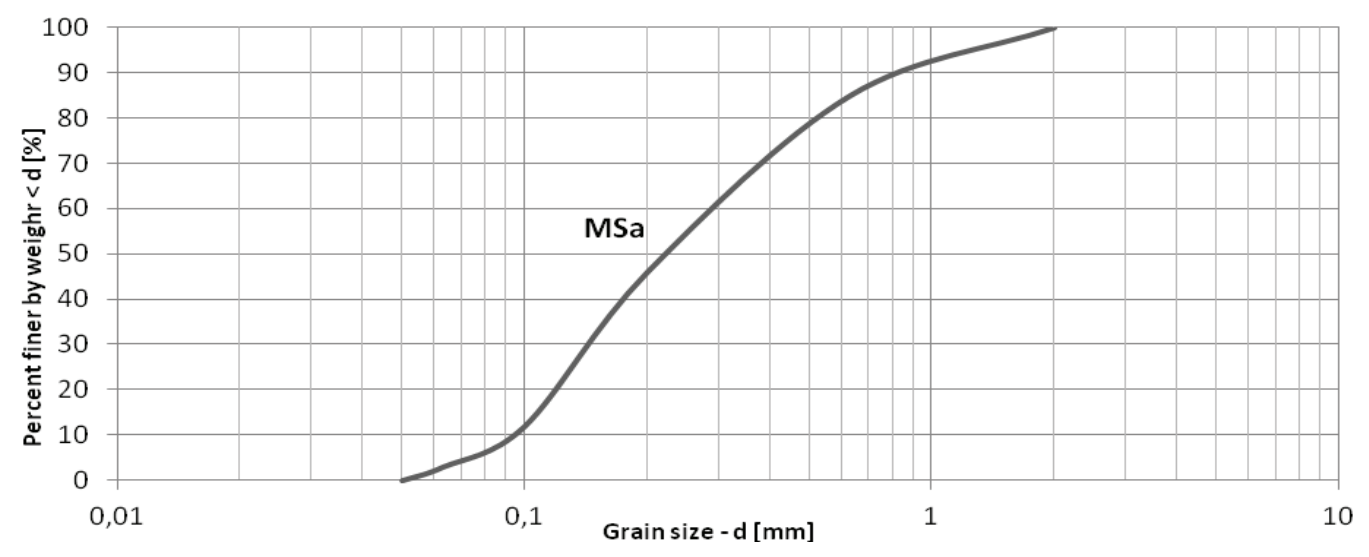

Fig. 1. Particle size distribution of test materials 
fied as medium sand (MSa), according to Eurocode 7. Figure 1 shows the particle size distribution curve of the test material.

The optimum water content was determined for RCA. The standard compaction energy equal $0.59 \mathrm{~J} / \mathrm{cm}^{3}$ and a cylinder with volume of $2.2 \mathrm{dm}^{3}$ was used. Optimum moisture content was equal to $8.67 \%$ and the maximum dry density was equal to $1.98 \mathrm{~g} / \mathrm{cm}^{3}$. The results of the proctor test are shown in Fig. 2.

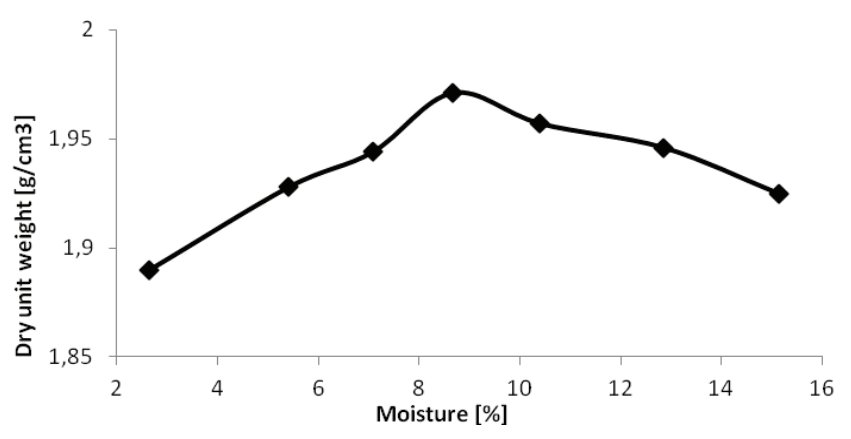

Fig. 2. The proctor test results for tested recycled concrete aggregate

Direct shear test was performed in two apparatus with square boxes: a medium one $(120 \times 120 \mathrm{~mm})$ and a large one $(250 \times 250 \mathrm{~mm})$. In each of these devices, 6 tests were carried out, 3 of them on air dry RCA and 3 of them after reaching optimum moisture content. Shear speed was set at $0.01 \mathrm{~mm} / \mathrm{min}$. Sample indexed as " $\mathrm{M}$ " has been sheared in the medium apparatus, while "L" means that sample has been sheared in the large device. Table 1 summarizes the properties of the material, testing conditions and the ratio of $L / D_{50}$.

Table 1. Test conditions for RCA direct shear tests

\begin{tabular}{|c|c|c|c|c|c|}
\hline Test No. & $\begin{array}{c}L / D_{50} \\
{[-]}\end{array}$ & $\begin{array}{c}\text { Water } \\
\text { content } \\
{[\%]}\end{array}$ & $\begin{array}{c}\text { Normal } \\
\text { stress } \\
{[\mathrm{kPa}]}\end{array}$ & $\begin{array}{c}\rho_{d} \\
{\left[\mathrm{~g} / \mathrm{cm}^{3}\right]}\end{array}$ & $\begin{array}{c}I_{d} \\
{[-]}\end{array}$ \\
\hline M1 & \multirow{6}{*}{545} & 2.21 & 48,73 & 1.881 & 0.665 \\
\hline M2 & & 2.01 & 71,38 & 1.883 & 0.667 \\
\hline M3 & & 2.13 & 85,42 & 1.887 & 0.669 \\
\hline M4 & & 8.59 & 50,21 & 1.963 & 0.736 \\
\hline M5 & & 8.71 & 70,87 & 1.972 & 0.742 \\
\hline M6 & & 8.35 & 84,26 & 1.961 & 0.734 \\
\hline L1 & \multirow{6}{*}{1136} & 2.15 & 49.25 & 1.889 & 0.669 \\
\hline L2 & & 2.02 & 69.14 & 1.882 & 0.662 \\
\hline L3 & & 2.10 & 84,69 & 1.886 & 0.668 \\
\hline L4 & & 8.56 & 49.91 & 1.968 & 0.735 \\
\hline L5 & & 8.69 & 70.64 & 1.971 & 0.741 \\
\hline L6 & & 8.43 & 83.75 & 1.961 & 0.731 \\
\hline
\end{tabular}

\section{RESULTS}

The test results are shown in Figs. 3 and 4. The data relating to the shear stress and the horizontal strain of the sample are presented in graphs.

In the case of both Figs. 3 and 4, the shear stresses are higher, when tested in medium apparatus. Differences in stresses are small, ranging from 1 to $4 \mathrm{kPa}$. Shear stress peaks in the medium box are more pronounced and easier to locate which may suggest jamming of the grains.

In Fig. 3, a characteristic which is very different for a shear stress can be seen - a horizontal strain for different values of normal stress. The shear occurs at various points, which may be caused by high angularity and roughness of the grains. However, with the increase in moisture content, the phenomenon disappears, and the shear process is the same for different values of normal stress, as can be seen in Fig. 4.

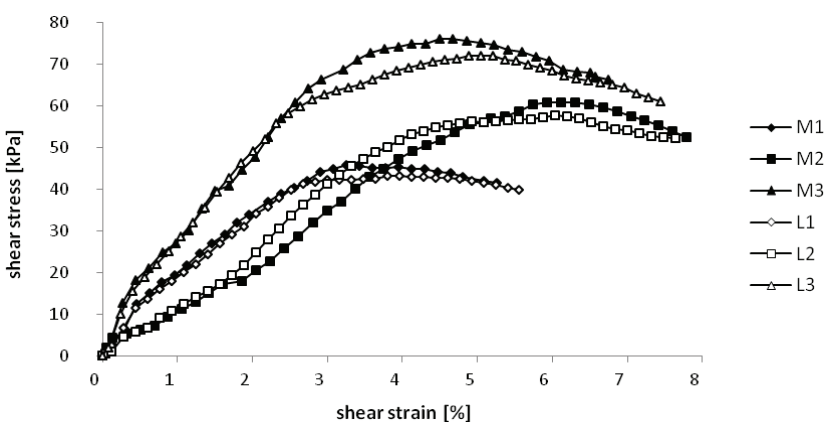

Fig. 3. Results of direct shear test in medium and large box for sample preparation with $2 \%$ water content

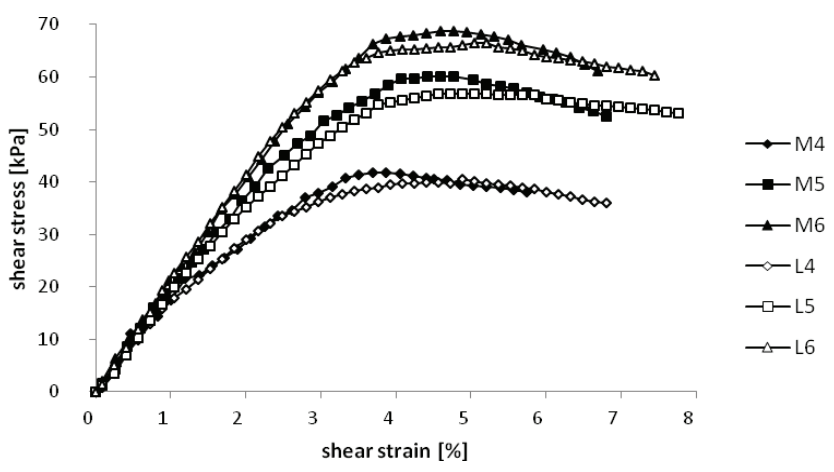

Fig. 4. Results of direct shear tests in medium and large box for sample preparation with $8 \%$ water content

Figure 5 shows the relationship between shear stress and normal stress for all the tests. Describing the mileage points on the basis of linear equations made it possible to determine friction angle, as shown 
in Table 2. For both dry and wet RCA, friction angle obtained from medium apparatus is higher by $1.2^{\circ}$ than values obtained from a larger device.

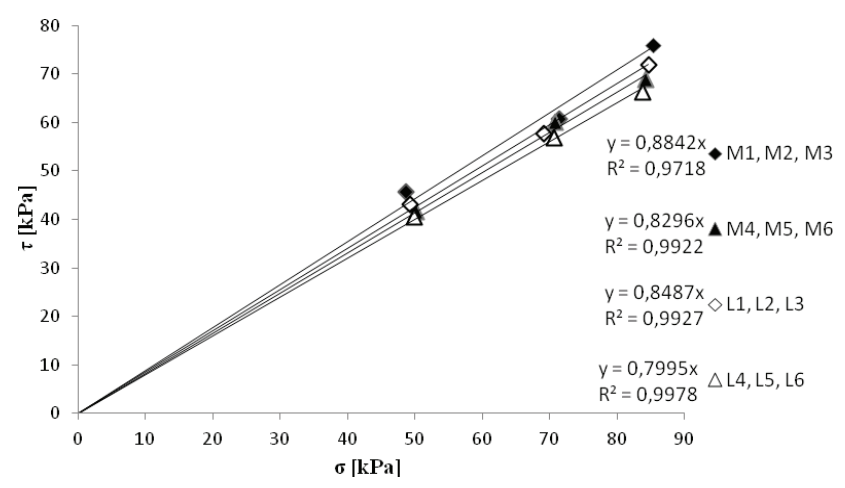

Fig. 5. Plot of shear stress to normal stress from direct shear tests for medium and large box

Table 2. Calculation results for friction angle

\begin{tabular}{|l|c|c|}
\hline \multicolumn{1}{|c|}{ Tests No. } & $\begin{array}{c}\text { Moisture } \\
{[\%]}\end{array}$ & $\begin{array}{c}\text { Friction angle } \\
{\left[{ }^{\circ}\right]}\end{array}$ \\
\hline M1, M2, M3 & $2.01-2.13$ & 41.5 \\
\hline M4, M5, M6 & $8.35-8.71$ & 39.7 \\
\hline L1, L2, L3 & $2.02-2.15$ & 40.3 \\
\hline L4, L5, L6 & $8.43-8.69$ & 38.5 \\
\hline Leighton buzzard sand [12] & Air dry & $49-50$ \\
\hline
\end{tabular}

\section{CONCLUSIONS}

This article presented the results of studies conducted on recycled concrete aggregate (RCA). Test were performed on two direct shear apparatus: medium and large to examine the scale effect. The following conclusions were reached in this paper:

1. The compaction at optimum water content makes the sample more homogeneous and repeatable.

2. The friction angle obtained from studies in average direct shear apparatus was higher by $1.2^{\circ}$ relative to the values obtained from the larger device, which explicitly says that the scale effect is also present for this material.

3. The $L / D_{50}$ ratio in both medium and large apparatus was much higher than 50 , which excludes the influence of particle size on the scale effect.

4. The authors believe that the main reason for the difference between friction angles obtained from different apparatus is the angularity and roughness of the material's particles. This causes the wedging of the grains in the medium box, which leads to higher shear stress and high friction angles.

5. In addition, influence of grain rotation on the results achieved during the shearing of both large and medium apparatus should be examined.

6. It seems reasonable to perform direct shear test of RCA at higher than normal stress, which authors have not done because of the apparatus' limitations.

\section{REFERENCES}

[1] Aurstad J., Berntsen G., PetKovic G., Evaluation of unbound crushed concrete as road building material - Mechanical properties vs field performance, 26th International Baltic Road Conference, 28-30 August 2006, Kuressaare, Estonia, Baltic Road Association, 2006.

[2] Aurstad J., Aksnes J., Dahlhaug J.E., Berntsen G., UTHUS N., Unbound crushed concrete in high volume roads - a field and laboratory study, 5th International Conference on Research and Practical Applications Using Wastes and Secondary Materials in Pavement Engineering, 22-23 February 2006 (14 p), Liverpool John Moores University, Liverpool 2006.

[3] Bareither C.A., Benson C.H., Edil T.B., Comparison of shear strength of sand backfills measured in small - scale and large - scale direct shear tests, Canadian Geotechnical Journal, 2008, Vol. 45(9), 1224-1236, DOI: 10.1139/T08-058.

[4] Bishop A.W., A large shear box for testing sands and gravels. Proceedings of the 2nd International Conference on Soil Mechanics and Foundation Engineering, Rotterdam, the Netherlands, 21-30 June 1948, 207-211.

[5] Cerato A.B., Lutenegger A.J., Specimen size and scale effects of direct shear box tests on sand, Geotechnical Testing Journal, 2006, Vol. 29(6), 507-516. DOI: 10.1520/GTJ100312.

[6] DadKhah R., GHafoori M., AJalloeian R., LASHKaripour G.R., The Effect of scale direct shear test on the strength parameters of clayey sand in Isfahan City, Iran. Journal of Applied Sciences, 2010, Vol. 10(18), 2027-2033, DOI: 10.3923/jas.2010.2027.2033.

[7] JeWell R.A., WRoth C.P., Direct shear tests on reinforced sand, Geotechnique, 1987, 37(1), 53-68.

[8] LI X., Recycling and reuse of waste concrete in China. Part I. Material behaviour of recycled aggregate concrete, Resources, Conservation and Recycling, 2008, 53(1), 36-44, DOI: 10.1016/j.resconrec.2008.09.006.

[9] LimbachiYa M.C., LeElawat T., DHIR R.K., Use of recycled concrete aggregate in high-strength concrete, Materials and Structures, 2000, 33(9), 574-580.

[10] Moayed R.Z., AlizadeH A., Effects of shear box size on the strength for different type of silty sands in direct shear tests, Unsaturated Soils: Theory and Practice, Kasetsart University, Thailand, 2011, 265-271..

[11] Padmini A.K., Ramamurthy K., Mathews M.S., Influence of parent concrete on the properties of recycled aggregate concrete, Construction and Building Materials, 2009, 23(2), 829-836, DOI: 10.1016/j.conbuildmat.2008.03.006

[12] Palmeria E.M., Milligan G.W.E., Scale effects in direct shear tests on sand, Proceedings of the 12th International Conference on Soil Mechanics and Foundation Engineering, Rio de Janerio, Brazil, 13-18 August 1989. 
[13] PoOn C.S., ChAN D., Feasible use of recycled concrete aggregates and crushed clay brick as unbound road sub-base, Construction and Building Materials, 2006, 20(8), 578-585, DOI: 10.1016/j.conbuildmat.2005.01.045.

[14] Sas W., SzymańsKi A., MalinowsKa E., Gabryś K., Geotechniczne uwarunkowania zastosowania materiatów antropogenicznych $w$ budownictwie, Inżynieria Morska i Geotechnika, 2012, 4, 376-380.

[15] SAS W., MaciorowsKa E., Wspótczynnik filtracji destruktu betonowego jako gruntu antropogenicznego oznaczany laboratoryjnie metoda stałogradientowa, Przegląd Naukowy - Inżynieria i Kształtowanie Środowiska, 2012, 58, 284-295.
[16] SAS W., SobanSKa K., Recykling jako sposób zagospodarowania odpadów powstajacych przy remontach dróg, Przegląd Naukowy - Inżynieria i Kształtowanie Środowiska, 2010, 47, 53-64.

[17] TAYlOR D.W., LePS T.M., Shearing properties of Ottawa standard sand as determined by the MIT strain-controlled direct shearing machine, Record of Proceedings of Conference on Soils and Foundations, US Corps of Engineers, Boston, Mass., June 1938.

[18] Zhou Q., Shen H.H., Helenbrook B.T., Zhang H., Scale dependence of direct shear tests, Chinese Science Bulletin, 2009, 54(23), 4337-4348. DOI: 10.1007/s11434-009-0516-5. 